\title{
INHERITANCE OF A PIT IN THE SKIN OF THE LEFT EAR
}

\author{
JAMEs ERnest Kindred \\ Biological Laboratory, Western Reserve University
}

$I^{\mathrm{N}}$ D DISCUSSING the characteristics of the ears of a group of people in connection with Schofield's paper (1917) on the inheritance of the bilobed ear, one of the members of the group called attention to the fact that she had a bi-lobed ear, but did not know of such a condition in any of her relatives. Her mother then remarked that she had a peculiar pit on the side of her left ear. Upon examination of this ear, a small pit was observed in the skin of the proximal end of the upper part of the helix. The accompanying sketch shows its relative position. My informant then told me that this pitting was a distinctive mark in her family and by carefully questioning her, I learned the following interesting facts concerning the inheritance of this peculiar marking. A graphic summary of the inheritance of this pit is given in the chart on the opposite page.

As far as the propistus could recollect, the marking was first noted in her paternal grandfather $(I, 1)$. Her father (II, 2), one of eight children, had the pitted condition, and although she did not know whether or not his sisters or brothers were so marked, it seems more than likely that they were, because some of her cousins had a pitted helix. In the third generation there were four individuals, 2 girls and 2 boys, with the pitted helix. The propistus (III, 7), is one of the girls, her daughter (IV, 7) does not have the pitted helix. The sister of the propistus (III, 9), also having the pitted helix, is married and has five children, one daughter $(I V, 8)$ having the pitted helix. None of the boys with pitted helix in generation III, married. Another sister of the propistus (III, 4), not pitted herself, is married and has six children, two boys and four girls. Both of the boys (IV, 4,5 ) have the

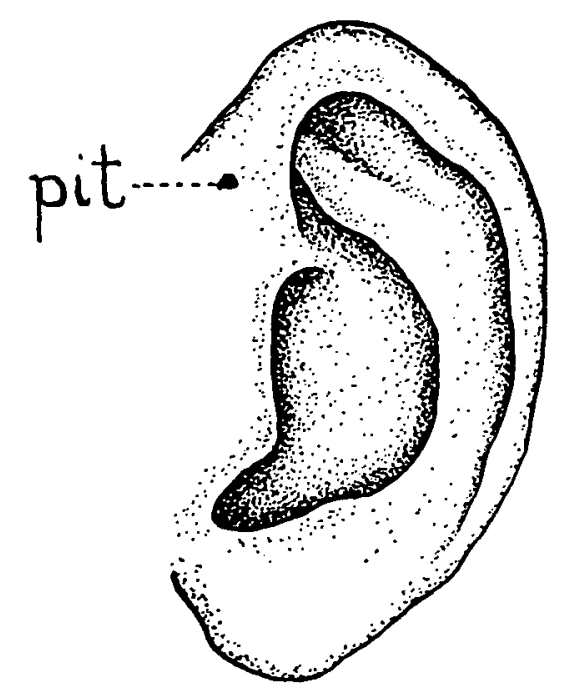

Position of the inherited pit. (Fig. 17.)

pitted helix. A brother of the propistus (III, 14) does not have the pitted helix, but his only son has. The propistus states that in all cases the marking is on the same spot of the same ear (left).

Thus in this fraternity there is some factor inherited which has to do with the formation of the skin in the region of the proximal end of the helix. The pitting occurs in some individuals of each generation from the time of its appearance and may be transmitted by individuals not marked themselves. Further. it may be transmitted by either sex. In some cases the offspring of unpitted parents are pitted, while in other cases the pit does not occur in the offspring of a mating in which one or the other of the parents is pitted. Judging from the manner of its appearance, the marking is neither dominant nor recessive, but must fall into the intermediate doubtful class of incomplete dominance. 


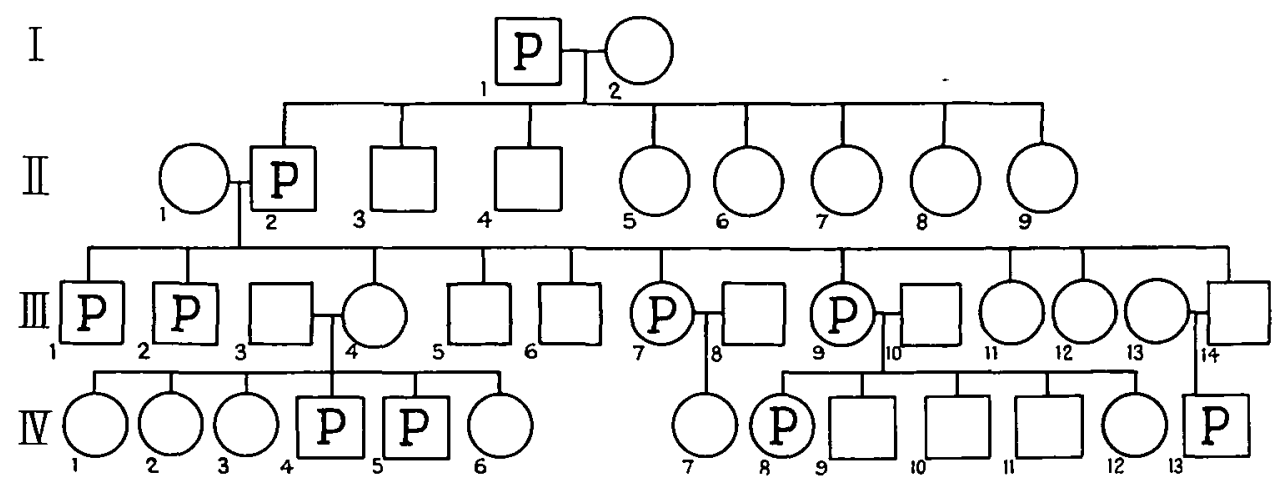

INHERITANCE OF PIT IN THE EAR THROUGH FOUR GENERATIONS

The propositus in this case is No. 7 in the third generation. Her grandfather (I, 1$)$ was the first known to have the pitted condition. He transmitted it to his son (II, 2), father of the propositus. He (II, 2) passed it on to four of his children as shown in the third generation. Two others of the third generation, not possessing the pit themselves, transmitted it to individuals in the fourth generation. It may also be seen that III, 7 did not transmit the condition to the next generation, but that III, 9 did. (Fig. 18.)

\section{A New Study of Eugenics}

The TREnd of THE Race: a study of present tendencies in the biological development of civilized mankind, by Samuel J. Holmes, Ph.D., professor of zoology in the University of California. Pp. 396, price \$4 net. New York, Harcourt, Brace \& Co., 1921.

Never before have the data of eugenics been subjected to such a thorough criticism as by Dr. Holmes. Entirely in sympathy with the principles underlying the eugenics movement, he has made a valuable contribution to it by his exhaustive treatment of the literature, particularly that from Europe. His conclusions generally accord with those accepted by other eugenists. The book is lacking in careful definitions of the terms used, and makes little attempt to suggest remedies for the various dysgenic trends noted. After a few introductory chapters on inheritance, and on the birth rate, it is devoted almost wholly to a consideration of the various selective influences at work on mankind. It is announced that a full bibliography of the subject is to be published separately.-P. P.

\section{For and Against Birth Control}

The Control of Parenthood, edited by James Marchant, introduction by the Bishop of Birmingham. Pp. 222. New York and London, G. P. Putnam's Sons, 1920.

Every intelligent person favors birth control-in one sense or another; but most intelligent persons reprobate the birth-control propaganda which has been a glaringly unscientific treatment of a biological subject. In this volume the problem is discussed by $\mathrm{J}$. Arthur Thomson, Leonard Hill, Dean Inge, Harold Cox, Mary Scharlieb, F. B. Meyer, A. E. Garvie, H. Rider Haggard and Marie C. Stopes, some being pro, some being contra, and one or two apparently "on the fence." The volume probably presents the sanest and most thoughtful discussion of the subject that is available, although the rhapsodical views of Dr. Stopes on "maternal impressions" hardly belong in a serious book. While nothing new is presented, the facts and arguments on both sides are brought forward in a way that should stimulate any responsible person to do a good deal of thinking, if his mind is not already closed on this topic.-P. P. 